\title{
Body size data collected non-invasively from drone images indicate a morphologically distinct Chilean blue whale (Balaenoptera musculus) taxon
}

\author{
Matthew S. Leslie ${ }^{1, *}$, Colin M. Perkins-Taylor ${ }^{1}$, John W. Durban ${ }^{2}$, \\ Michael J. Moore ${ }^{3}$, Carolyn A. Miller ${ }^{4}$, Proud Chanarat ${ }^{5}$, Paulina Bahamonde ${ }^{6,7}$, \\ Gustavo Chiang ${ }^{7,8}$, Amy Apprill ${ }^{4}$ \\ ${ }^{1}$ Department of Biology, Swarthmore College, 500 College Ave., Swarthmore, PA 19081, USA \\ ${ }^{2}$ Southall Environmental Associates, Inc., 9099 Soquel Drive, Suite 8, Aptos, CA 95003, USA \\ ${ }^{3}$ Biology Department, Woods Hole Oceanographic Institution, 266 Woods Hole Rd., MS \#50, Woods Hole, MA 02543, USA \\ ${ }^{4}$ Marine Chemistry \& Geochemistry Department, Woods Hole Oceanographic Institution, 266 Woods Hole Rd., MS \#4, \\ Woods Hole, MA 02543, USA \\ ${ }^{5}$ WWF Thailand, Level 3, 9 Pra Dipat 10, Pra Dipat Road, Phaya Thai, Bangkok 10400, Thailand \\ ${ }^{6}$ HUB AMBIENTAL UPLA - Centro de Estudios Avanzado, Universidad de Playa Ancha, Valparaíso 2340000, Chile \\ ${ }^{7}$ Melimoyu Ecosystem Research Institute, Avenida Kennedy 5682, Santiago de Chile 7650720, Chile \\ ${ }^{8}$ CAPES-UC, Center for Applied Ecology \& Sustainability, Pontificia Universidad Catolica de Chile, Santiago 8331150, Chile
}

\begin{abstract}
The blue whale Balaenoptera musculus (Linnaeus, 1758) was the target of intense commercial whaling in the $20^{\text {th }}$ century, and current populations remain drastically below prewhaling abundances. Reducing uncertainty in subspecific taxonomy would enable targeted conservation strategies for the recovery of unique intraspecific diversity. Currently, there are 2 named blue whale subspecies in the temperate to polar Southern Hemisphere: the Antarctic blue whale $B$. $m$. intermedia and the pygmy blue whale $B . m$. brevicauda. These subspecies have distinct morphologies, genetics, and acoustics. In 2019, the Society for Marine Mammalogy's Committee on Taxonomy agreed that evidence supports a third (and presently unnamed) subspecies of Southern Hemisphere blue whale subspecies, the Chilean blue whale. Whaling data indicate that the Chilean blue whale is intermediate in body length between pygmy and Antarctic blue whales. We collected body size data from blue whales in the Gulfo Corcovado, Chile, during the austral summers of 2015 and 2017 using aerial photogrammetry from a remotely controlled drone to test the hypothesis that the Chilean blue whale is morphologically distinct from other Southern Hemisphere blue whale subspecies. We found the Chilean whale to be morphologically intermediate in both overall body length and relative tail length, thereby joining other diverse data in supporting the Chilean blue whale as a unique subspecific taxon. Additional photogrammetry studies of Antarctic, pygmy, and Chilean blue whales will help examine unique morphological variation within this species of conservation concern. To our knowledge, this is the first non-invasive small drone study to test a hypothesis for systematic biology.
\end{abstract}

KEY WORDS: Aerial photogrammetry - Taxonomy - Subspecies - Whaling - Systematics · Unoccupied aerial systems · UAS

\section{INTRODUCTION}

Overharvest in the oceans extends up the macroscopic marine food web (Hutchings \& Reynolds 2004)

\footnotetext{
*Corresponding author: mleslie2@swarthmore.edu
}

all the way to the largest species of whales (Clapham \& Baker 2018). Due to its large size (lengths exceeding $30 \mathrm{~m}$ ), the blue whale Balaenoptera musculus (Linnaeus 1758) was a primary target of industrial-

() The authors 2020. Open Access under Creative Commons by Attribution Licence. Use, distribution and reproduction are unrestricted. Authors and original publication must be credited. 
scale commercial whaling (summarized in Branch et al. 2007). Industrial whaling began in the early $20^{\text {th }}$ century and officially ended with a 1965-1966 International Whaling Commission ban on the harvest of blue whales, although some illegal whaling continued through the 1970s (Branch et al. 2004, Clapham \& Baker 2018). The global population of blue whales is listed as Endangered under the IUCN Red List (Cooke 2018). Of the Southern Hemisphere subspecies, the Antarctic blue whale B. m. intermedia (Burmeister 1871) is estimated to have been the most impacted by commercial whaling (>340 000 killed), and their current abundance is estimated to be approximately $1 \%$ of the pre-exploitation population size (Branch et al. 2004). This taxon is listed as Critically Endangered by the IUCN (Cooke 2018). By comparison, the pygmy blue whale $B$. m. brevicauda (Ichihara 1966) is considered to have been less impacted (Branch et al. 2007), although this is not as well understood because the pygmy blue whale was not described as a subspecies until 1966 (Ichihara 1966). The IUCN has not evaluated the pygmy blue whale's conservation status since 1998 (Pollock 2019), at which time it was listed as Data Deficient (Torres-Florez et al. 2014).

Accurate taxonomy is a requisite component for efficient and effective conservation measures. Uncertainty still permeates our knowledge of cetacean taxonomy, hindering conservation efforts, and this taxonomic uncertainty extends to the blue whale. Currently, there are 4 named subspecies of blue whale recognized by the Committee on Taxonomy of the Society for Marine Mammalogy (SMM) (Committee on Taxonomy 2019): the nominate subspecies in the Northern Hemisphere (B. m. musculus), a tropical subspecies in the northern Indian Ocean $(B . m$. indica [Blyth, 1859]), and 2 Southern Hemisphere subspecies (the Antarctic blue whale and the pygmy blue whale). In addition, an unnamed Chilean subspecies of blue whale is listed as an unnamed subspecies by the SMM (Committee on Taxonomy 2019) based on the results of Bayesian mixture models of length frequencies of sexually mature female blue whales taken in Southern Hemisphere whaling (Branch et al. 2007). As a result of whaling, the 1998 abundance of the Chilean blue whale population was estimated to be $7.2-9.5 \%$ of pre-exploitation levels (Williams et al. 2011). Although the population shows signs of recovery, it still has low abundance (Galletti Vernazzani et al. 2017).

In the Southern Hemisphere, the Antarctic and pygmy blue whale subspecies differ in their distributions, morphologies, acoustics, and genetics. During the austral summer, the 2 subspecies occupy different ranges: Antarctic blue whales are found south of $54^{\circ} \mathrm{S}$ while pygmy blue whales are found in the Indian Ocean, south of the tropical distribution of B. m. indica and north of $54^{\circ} \mathrm{S}$ (Branch et al. 2007, Pastene et al. 2020). Morphologically, the Antarctic blue whale is much larger than the pygmy blue whale with a greater maximum length (>30 vs. $24.1 \mathrm{~m})$, a greater mean length at sexual maturity ( 23.7 vs. $19.2 \mathrm{~m}$ ), larger baleen plates relative to body size, and a proportionally larger tail region (Mackintosh \& Wheeler 1929, Ichihara 1966, Branch et al. 2007). Antarctic and pygmy blue whales also have structurally different acoustic calls (McDonald et al. 2006). Furthermore, these 2 Southern Hemisphere subspecies differ genetically (LeDuc et al. 2007), although they are not separated by fixed diagnostic nucleotides and are known to hybridize (Attard et al. 2012).

Acoustic and genetic evidence supports the Chilean blue whale as a third Southern Hemisphere subspecies inhabiting the Pacific Ocean off western South America (McDonald et al. 2006, LeDuc et al. 2007, 2017, Torres-Florez et al. 2014, Buchan et al. 2018). Acoustic studies of blue whale song in the Southern Hemisphere have recorded 3 unique, structurally different blue whale songs in Antarctica, the Indian Ocean, and Chile (McDonald et al. 2006), indicating that whales from these localities are distinct from one another. This is supported by contemporary genetic data, as Chilean blue whales differ genetically from Antarctic and pygmy blue whales, with similar degrees of genetic differentiation between all 3 groups (LeDuc et al. 2007, 2017). Furthermore, hundreds of blue whales have been observed off the coasts of Chile, Peru, and Ecuador during the austral summer when Antarctic and pygmy blue whales are mainly located farther south in or near the Southern Ocean off Antarctica (Williams et al. 2011, Galletti Vernazzani et al. 2017), which suggests that this area is occupied by another blue whale population with a unique distribution. This distribution may include the southern portion of the eastern tropical Pacific (ETP), as Chilean blue whales migrate from the Gulfo Corcovado to the Galapagos Archipelago during the austral winter (Hucke-Gaete et al. 2018, Torres-Florez et al. 2015). Using body length measurements collected by whaling operations, Branch et al. (2007) found sexually mature Chilean blue whales to be intermediate in size between pygmy and Antarctic blue whales. Branch et al. (2007) proposed the Chilean blue whale as a unique subspecies, but did not provide a name or a nomenclatural treatment. 
They presented data to support this unique subspecific taxon under the following definition of a subspecies (Branch et al. 2007, p. 828):

a group of individuals from the same species that is geographically distinct and recognizably different (in terms of morphology, genetics, or behavior) but could interbreed with another subspecies if they shared the same habitat

In a recent analysis of morphometric data of whales killed off Chile by a Japanese whaling company during 1965-1966, Pastene et al. (2020) found that sexually mature female and male Chilean blue whales are intermediate in maximum body length and mean body length between pygmy and Antarctic blue whales. This evidence further supports the findings of Branch et al. (2007). However, contemporary morphometric data of blue whales are very limited. This is in contrast with the genetic and acoustic blue whale data, both of which are contemporary.

In this study, we collected morphological measurements of free-swimming Chilean blue whales using aerial photogrammetry via remotely controlled drones and compared our measurements to whaling data to test the hypothesis that the Chilean blue whale is morphologically distinct from Antarctic and pygmy blue whales.

\section{MATERIALS AND METHODS}

\subsection{Drone photogrammetry of Chilean blue whales}

This study was conducted during the austral summers of 2015 (22 February to 8 March) and 2017 (15 February to 1 March) in the Gulfo Corcovado from the Gulfo de Ancud to the Moraleda Channel-known blue whale feeding areas in southern Chile (Fig. 1; Thiele et al. 1998, Hucke-Gaete et al. 2004). All research activities were carried out with appropriate permits from the Ministerio de Economia, Fomento y Turismo, Subsecreteria de Pesca y Acuicultura: MERI 488-FEB-2015 and MERI 488-FEB-2017. An APH-22 hexacopter (Aerial Imaging Solutions; described in detail by Goebel et al. 2015) was used to photograph blue whales from an altitude ranging from 51-64 m following protocols described by Durban et al. (2016). In 2015, a total of 59 flights were conducted over blue whales, with 37 successfully capturing photographs of a total of 13 whales. In 2017, we flew over blue whales 16 times. Of these 16 flights, 9 successfully captured blue whale photographs. A total of 23 unique blue whales were identified based on skin pigmentation patterns, distinctive markings, and scars, using aerial

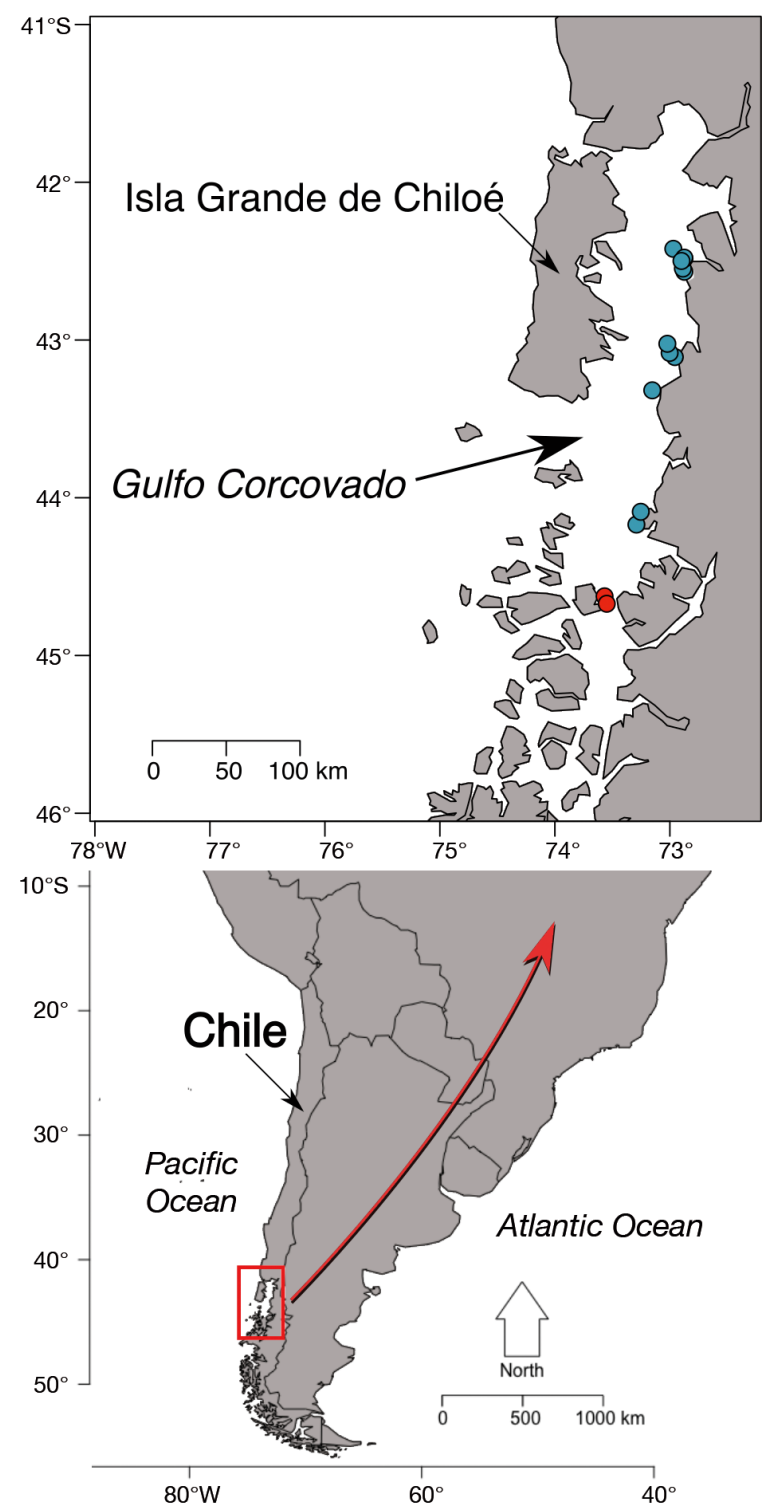

Fig. 1. Gulfo Corcovado, Chile (upper), in relation to South America (bottom). Dots: locations where blue whales included in these analyses were measured using aerial photogrammetry via drones (blue: 2015; red: 2017)

and boat-based images (see Gilpatrick \& Perryman 2008). To ensure the accuracy of length measurements, we only used photographs showing the entire body of the whale flat at the surface with the nostrils and dorsal fin clearly visible. A total of 13 whales from 2015 were measured using 1-7 images ind. ${ }^{-1}$, and 2 whales from 2017 were measured using 1-5 images ind. ${ }^{-1}$. Multiple images were generally taken of the same whale. In this case, the image with the longest body length measurement was selected as corresponding to the flattest surfacing orientation, and therefore the most accurate representation of its total length. The total body length, 
head length, and tail length for each whale were measured photogrammetrically as previously described by Durban et al. (2016): barometric altitude, camera focal length, pixel width, and pixel counts were obtained using Adobe Photoshop (Adobe) or Image J (Schneider et al. 2012) and used to calculate whale measurements. Total body length was measured from the tip of the rostrum to the notch between the tail flukes (total length), head length was measured from the tip of the rostrum to the mid-point of the nostrils (rostrumnostrils), and tail length was measured from the trailing edge of the dorsal fin to the notch between the tail flukes (dorsal fin-fluke) (Fig. 2; Gilpatrick \& Perryman 2008). To examine differences in head and tail lengths without the impact of allometric scaling, we converted these values to relative values by making them a percentage of the total body length of the individual. Durban et al. (2016) demonstrated the accuracy of this method by showing less than $5 \%$ variability in average body lengths estimated from $4-7$ repeat measurements for 6 whales.

\subsection{Whaling records}

\subsubsection{Subspecies-level comparisons}

To test the hypothesis of the Chilean blue whale's subspecies independence, we compared total body length, relative head length, and relative tail length of Chilean, Antarctic, and pygmy blue whales using our photogrammetric measurements from Chile and historical measurement data from Chilean, Antarctic, and pygmy blue whales obtained from whaling records. Historical data from Chilean blue whales were collected during a 1965-1966 Japanese whaling operation (Pastene et al. 2020). Morphometric data for Antarctic blue whales were collected from whaling records from the British Discovery Expeditions

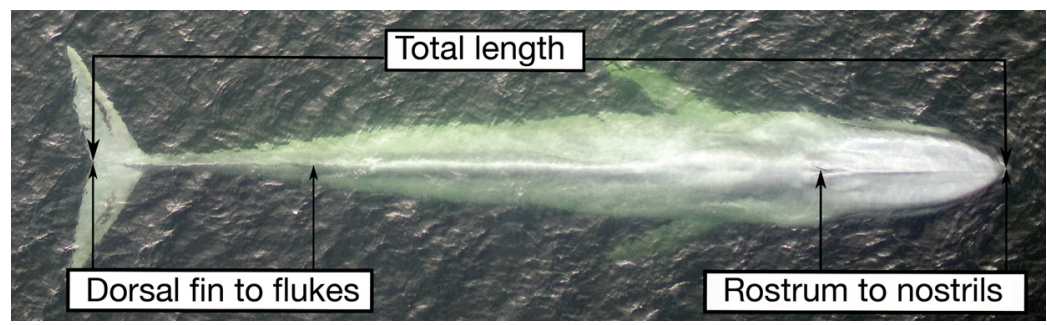

Fig. 2. Example photograph taken from a small drone that met criteria to use for contemporary Chilean blue whale morphological measurements. Total length was measured from tip of the rostrum to the notch between the tail flukes; head length was measured from the tip of the rostrum to the mid-point of the nostrils; and tail length was measured from the trailing edge of the dorsal fin to the notch between the tail flukes between 1925 and 1927 at South Georgia Island and South Africa (Mackintosh \& Wheeler 1929). For pygmy blue whales, data from a 1960-1963 Japanese whaling operation in the Kerguelen Islands, the Crozet Islands, and around Marion Island were used (Ichihara 1966; later reported by Omura 1984).

In an effort to conduct unbiased comparisons of the different subspecies, we standardized our approach to select data that only included mature whales. This is important because immature Antarctic blue whales can overlap in total length with mature pygmy blue whales (and presumably Chilean blue whales; Branch et al. 2007), and all blue whale subspecies have been shown to have negative allometric growth for the caudal peduncle (Ortega-Ortiz et al. 2018). To avoid these issues and minimize the inclusion of immature whales, we only included individuals from each data set that met the minimum length threshold for sexually mature females within a subspecies (or putative subspecies), as described below. The female cut-off was used because the sex of the contemporary Chilean blue whales photographed by drones was not known; therefore, using the larger female cut-off ensures that we did not include any immature whales of either sex. Despite knowing the sex of whales in the whaling records, we also applied the within-subspecies female cut-off approach to the whaling data in order to standardize comparisons of drone and whaling data. In other words, only measurements of male and female whales taken from the whaling records that met the maturity length threshold for their respective subspecies were included in the analyses. Pastene et al. (2020) estimated the length when $50 \%$ of Chilean blue whale females are sexually mature to be $21.3 \mathrm{~m}$. Therefore, we included only individuals $\geq 21.3 \mathrm{~m}$ in both Chilean blue whale data sets. For pygmy blue whales, only individuals $\geq 19.2 \mathrm{~m}$ in total length were included for the same reason as Chilean blue whales (Ichihara 1966, Branch \& Mikhalev 2008, Pastene et al. 2020). For Antarctic blue whales, only individuals $\geq 23.4 \mathrm{~m}$ in total length were included because this is the estimated length when $50 \%$ of females are sexually mature (Branch \& Mikhalev 2008, Pastene et al. 2020). After removing individuals based on these total length criteria, removing any Chilean whales that were not photographed according to the standard of Durban et al. (2016), and removing individuals from whaling data that were outliers based on a regression of 2 head measurements and 2 tail meas- 
urements (Figs. S1 \& S2 in the Supplement at www. int-res.com/articles/suppl/n043p291_supp.pdf), the sample size was 11 Chilean blue whales (drone data), 56 Chilean blue whales (whaling data), 58 pygmy blue whales, and 332 Antarctic blue whales.

Total body lengths were compared across all 4 data sets directly. Furthermore, dorsal measurements of relative head length (rostrum-nostrils/total length) and relative tail length (dorsal fin-flukes/total length) collected via drone were directly compared to the same dorsal measurements of Antarctic and pygmy blue whales (Mackintosh \& Wheeler 1929, Ichihara 1966, Omura 1984). It is important to note, however, that not all measurements were reported for every individual. The historical Chilean blue whale records were also not included in these comparisons because dorsal measurements were not reported for this data set.

\subsubsection{Comparing sources of Chilean blue whale data}

Prior to testing for subspecies differences, we compared the drone-derived data and data from whaling for the Chilean blue whale population. We refer to them separately as Chilean (drone) and Chilean (whaling). While our Chilean (drone) data were directly comparable to the Antarctic and pygmy blue whale records because they had corresponding measurements, only total length was directly comparable between the 2 Chilean blue whale data sets. Instead of dorsal measurements of head length (rostrumnostrils) and tail length (dorsal fin-fluke), the Chilean (whaling) records reported a lateral head measurement (rostrum-eye) and a ventral tail measurement (anus-flukes). Therefore, before making comparisons between the Chilean (drone) and Chilean (whaling) data sets, we used the Antarctic and pygmy whaling records (which included dorsal, lateral, and ventral measurements) to model the allometric relationships between these different measurements. This allowed us to predict the lateral head and ventral tail measurements for the Chilean blue whales measured using drones.

To accomplish this estimation, we created 2 multiple linear regression models to estimate rostrum-eye length based on rostrum-nostrils length and total length, and anus-fluke length based on dorsal finfluke length and total length:

Model 1: rostrum-eye $=y_{1}+a_{1}(\mathrm{RBH})+b_{1}(L)$

Model 2: anus-fluke $=y_{2}+a_{2}(\mathrm{DFF})+b_{2}(L)$ where rostrum-eye = predicted rostrum-eye length (in $\mathrm{m}$ ), $y_{1}=$ the $y$-axis intercept, $a_{1}=$ head allometric coefficient, $\mathrm{RBH}=$ the measured rostrum-nostrils length (in $\mathrm{m}$ ), $b_{1}=$ relative head to body length allometric coefficient, $L=$ total length of the body (in $\mathrm{m}_{\text {; }}$ same for both models), anus-fluke = predicted flukeanus length (in $\mathrm{m}$ ), $y_{2}=$ the $y$-axis intercept, $a_{2}=$ tail allometric coefficient, DFF $=$ the measured flukedorsal fin length (in $\mathrm{m}$ ), and $b_{2}=$ relative tail to body length allometric coefficient.

Prior to building the models, we examined the relationship of the variables using a simple regression with the Antarctic and pygmy blue whale data. During this process, we discovered and removed 5 head length measurements and one tail length measurement because they were outliers and appeared to be erroneous (Figs. S1 \& S2). Both models had a strong positive correlation between the dorsal, lateral, and ventral measurements for relative head and tail length (Figs. S3 \& S4), indicating that rostrum-nostrils length is an accurate predictor of rostrum-eye length for head length, and dorsal fin-fluke length is an accurate predictor of anus-fluke length for tail length. These predicted values were therefore used to make comparisons with observed measurements. For these comparisons, head and tail lengths were converted to a measure relative to total body length.

\subsection{Data analysis}

We tested for differences between Antarctic, pygmy, and Chilean blue whales in total length, relative head length, and relative tail length. All analyses were performed in R v.3.6.1 ( $R$ Core Team 2020). Plots were also generated in R, using 'ggplot2' (Wickham 2016) with the 'Zissou1' color palette from the Wes Anderson Palette Generator (https://github. com/karthik/wesanderson). The data for each blue whale group were tested for normality using a Shapiro-Wilk test, from the 'baseR' package (R Core Team 2020), as well as Normal $Q-Q$ plots of the residuals of the total length of each group, using the 'stats' package of R (R Core Team 2020). While most of the data were normally distributed, the total length measurement for the Antarctic and the Chilean (whaling) data as well as the anus-fluke measurement for the pygmy blue whale data were not normally distributed. For each of these non-normal data subsets, the mean and median were within $0.15 \mathrm{~m}$ of one another. The close proximity of the mean and median indicate that the use of parametric statistics is probably sufficient. However, to be con- 
servative, we performed non-parametric statistics because statistical comparisons between these groups could be biased by high variance in sample sizes (11-332), as well as differing levels of variance of each group. To correct for these differences in variance between groups when performing statistical tests, all data were log transformed prior to performing the statistical analyses. Plots of log-transformed data can be found in Figs. S5 \& S6. We then performed the Kruskal-Wallis (Kruskal and Wallis 1952) 1-way ANOVA: a non-parametric test for significant differences from independent samples with differing sample size. To test pairwise differences between the groups, we performed pairwise Wilcoxon ranksum tests with Benjamini-Hochberg (Benjamini \& Hochberg 1995) correction for multiple tests, using the 'stats' package in R ( $\mathrm{R}$ Core Team 2020), and Dunn's post hoc tests (Dunn 1964) with Bonferroni correction (Dunn 1961) using the 'dunn.test' package (Dinno \& Dinno 2017). Non-transformed data were also analyzed with the same tests, and are available in Tables S1 and S2.

\section{RESULTS}

Mean length measurements shown in Table 1 include data collected in the field (via drone and whaling) and data estimated with multiple linear regression models. Lateral head and ventral tail measurements generated with regression models for Chilean (drone) data are consistent with the pattern of the original dorsal head and tail measurements. For example, in all measurements (measured in the field and estimated with regression models), the Chilean (drone) lengths are intermediate between the Antarctic and pygmy blue whale lengths. For all comparisons of head and tail lengths that follow, we use the rostrum-eye and anus-flukes measures, as this approach limits the number of estimations.

\subsection{Chilean data set comparisons}

The average $( \pm \mathrm{SD})$ total body length of the Chilean blue whales measured by drone was $22.45 \pm 0.67 \mathrm{~m}$ (Table 1, Fig. 3). This measure is similar to the average Chilean (whaling) lengths $(22.49 \pm 0.83 \mathrm{~m})$ and not statistically different when tested using non-parametric Wilcoxon test $(p=0.939)$ and Dunn's test $(p=1.000)$ (Table 2). The average relative head (rostrum-eye) lengths were also similar (20.71\% for Chilean drone vs. $19.92 \%$ for Chilean whaling data; see Table 1, Fig. 3),

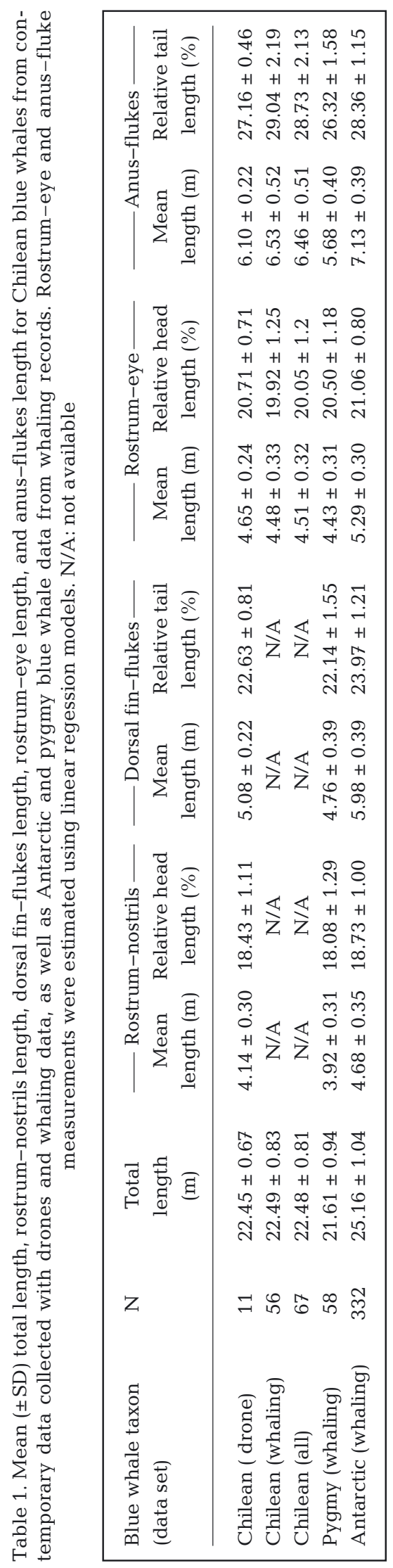



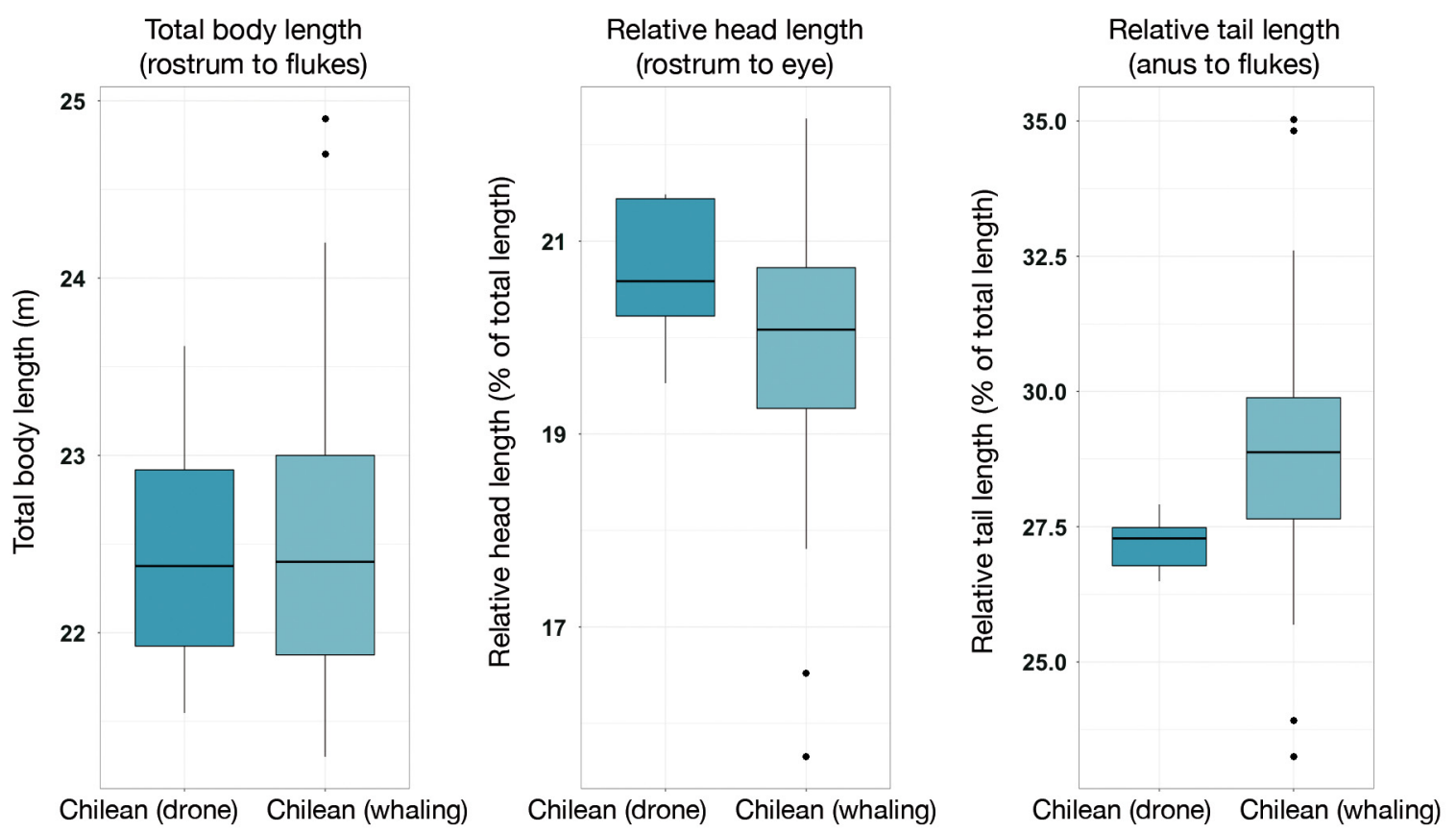

Fig. 3. Comparisons of 3 morphological measurements of Chilean blue whales collected via drone and from historical whaling data. Total body length was measured from the rostrum to notch in tail flukes. Head length was measured from the rostrum to the eye; this was measured directly from whaled specimens, but estimated using (a linear model) from the measured dorsal data for the recent Chilean whales. Similarly, tail measurements for whales killed during whaling were directly measured from the anus to the notch in the tail flukes. Lateral and ventral measurements for Chilean (drone) were estimated from the dorsal measurements (dorsal fin to notch in tail flukes) for the recent whales. Head and tail lengths are a percentage of the total length. Horizontal lines in the colored boxes: median of their respective group; colored boxes: first and third quartile; black vertical whiskers: from the hinge to the largest and smallest value no further than 1.5 times the inter-quartile range; black dots: data points $>1.5$ times the inter-quartile range from the box

Table 2. Results of 2 non-parametric pairwise tests for differences between the 2 sources of Chilean data based on logtransformed measurements of total body length, relative head (rostrum-eye), and relative tail (anus-flukes) lengths. The p-values were calculated using Kruskal-Wallis tests with Wilcoxon pairwise tests and Benjamini and Hochberg adjustments for multiple tests, and Dunn's post hoc tests with a Bonferroni correction. Shading indicates $\mathrm{p}<0.05$

\begin{tabular}{|lccc|}
\hline & Total length & Relative head & Relative tail \\
\hline Wilcoxon & 0.939 & 0.060 & $<0.001$ \\
Dunn & 1.000 & 0.039 & $<0.001$ \\
\hline
\end{tabular}

and not significantly different using Wilcoxon test $(\mathrm{p}=$ 0.060). However, relative head lengths were different when tested with Dunn's test $(p=0.039$; Table 2$)$. We also observed a statistical difference between the 2 Chilean blue whale data sets using both non-parametric tests for relative tail length $(\mathrm{p}<0.001$; Table 3$)$. The Chilean (drone) data set was slightly shorter in average relative tail length $(27.16 \%)$ compared to the Chilean (whaling) data (29.04\%) and had much less variance (SD: 0.46) compared to Chilean (whaling) data (SD: 2.19) (Table 1, Fig. 3).

\subsection{Subspecies comparisons}

After combining the 2 sources of data, Chilean blue whales $(22.48 \pm 0.81 \mathrm{~m})$ were $0.87 \mathrm{~m}$ longer in average body length than the pygmy blue whale $(21.61 \pm$ $1.04 \mathrm{~m}$ ) and $2.68 \mathrm{~m}$ shorter than the Antarctic blue whale (25.16 \pm 1.04$)$ (Table 1, Fig. 4). The Antarctic blue whale was significantly longer than both the Chilean blue whale and the pygmy blue whale (Table 3, Fig. 4). All pairwise subspecies comparisons of average total body length were statistically different using the Wilcoxon test ( $p<0.001$; Table 3 ). The total length comparison between pygmy and Chilean blue whales was not significant using Dunn's post hoc test ( $\mathrm{p}=$ 0.304; Table 3). All other comparisons between subspecies were statistically different with Dunn's post hoc test $(\mathrm{p}<0.001$; Table 3$)$.

Average relative head lengths (rostrum-eye) across all groups were within a range of $1.01 \%$ of each other, from $20.05-21.06 \%$ of total body length (Table 1 ; center frame of Fig. 4). Using Wilcoxon and Dunn's tests (Table 3), the pygmy blue whale and the Chilean blue whale's relative head lengths (rostrum-eye) were not significantly different $(p=0.140$ and $p=0.461$, re- 
Table 3. Non-parametric pairwise tests for differences between Southern Hemisphere blue whales based on log-transformed measurements of dorsal total body, relative head, and relative tail lengths. Pairwise p-values above the diagonal are for total body length, and below the diagonal are for (left cells) relative head (rostrum-nostrils) and (right cells) relative tail (dorsal fin-flukes). p-values were calculated using Kruskal-Wallis tests with Wilcoxon pairwise tests and Benjamini and Hochberg adjustments for multiple tests $(W)$ and Dunn's post hoc tests $(D)$ with a Bonferroni correction. Shading indicates $\mathrm{p}<0.05$

\begin{tabular}{|c|c|c|c|c|c|c|}
\hline & & \multicolumn{2}{|c|}{ Chilean (all) } & \multicolumn{2}{|c|}{ Pygmy } & Antarctic \\
\hline \multirow[t]{2}{*}{ Chilean (all) } & $W$ & \multirow{2}{*}{\multicolumn{2}{|c|}{-}} & \multicolumn{2}{|c|}{$<0.001$} & $<0.001$ \\
\hline & $D$ & & & \multirow{3}{*}{\multicolumn{2}{|c|}{0.304}} & $<0.001$ \\
\hline \multirow[t]{2}{*}{ Pygmy } & $W$ & 0.140 & $<0.001$ & & & $<0.001$ \\
\hline & $D$ & 0.461 & $<0.001$ & & & $<0.001$ \\
\hline \multirow[t]{2}{*}{ Antarctic } & $W$ & $<0.001$ & 0.54 & $<0.001$ & $<0.001$ & \multirow[t]{2}{*}{-} \\
\hline & $D$ & $<0.001$ & 1.000 & $<0.001$ & $<0.001$ & \\
\hline
\end{tabular}

were within $2.41 \%$ of one another (Table 1 ; right frame of Fig. 4), from 26.32-28.73\% of total body length. The average relative tail length of the Chilean and Antarctic blue whales were not significantly different $(\mathrm{p}=0.540$ with Wilcoxon and $\mathrm{p}=$ 1.000 with Dunn's tests), and both were significantly longer than the pygmy blue whale $(p<0.001$ in all tests; Table 3$)$.

\section{DISCUSSION}

\subsection{Chilean data set comparisons}

Chilean blue whales measured with drone photogrammetry were the same total length as Chilean blue whales killed

spectively). The Antarctic and Chilean blue whales were different in relative head length $(p<0.001$ for Wilcoxon and Dunn's tests; Table 3). Finally, Antarctic blue whales were significantly larger in relative head length than the pygmy blue whale $(p<0.001$ for both tests; Table 3).

Average relative tail lengths (dorsal anus-flukes) for the 3 groups of Southern Hemisphere blue whales during Japanese whaling; however, relative length of head and tail of Chilean whales differed in some of our tests. Relative head length was significantly longer in Chilean (drone) data compared to Chilean (whaling) using one statistical test. Given that these 2 samples were the same overall size, it makes sense that relative tail length was therefore significantly shorter in the Chilean (drone) sample compared to
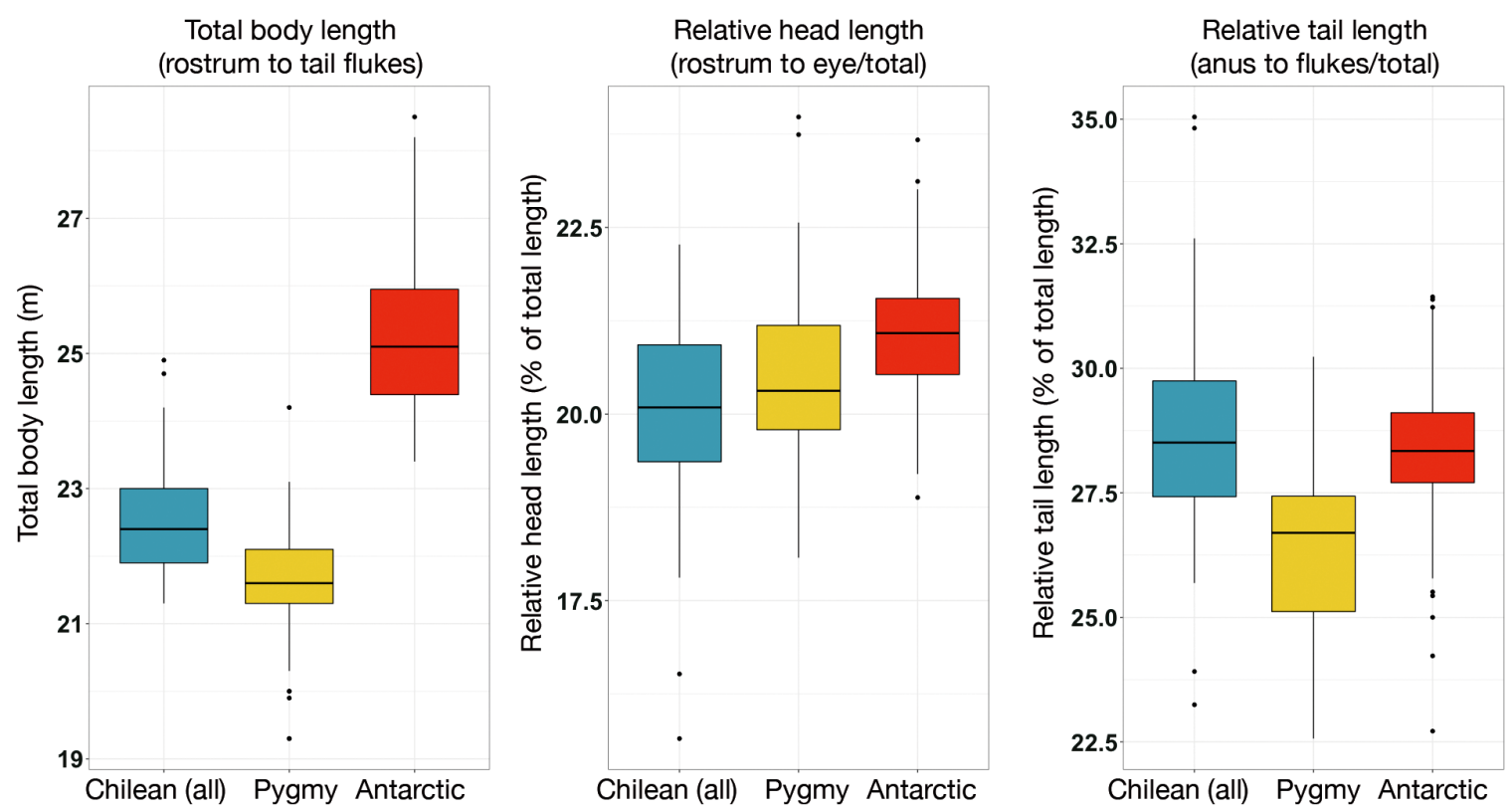

Fig. 4. Total body length and relative head and tail lengths ( $\%$ of total length) for 3 Southern Hemisphere blue whale subspecies. Total body length was measured from the tip of the rostrum to the notch between the tail flukes. Relative head and tail length data for the pygmy, Antarctic, and some Chilean blue whales were measured directly from dead specimens along the lateral surface from rostrum-eye and anus-flukes, respectively. Chilean measurements are a combination of whaling data and drone measurements. Horizontal lines in the colored boxes show the median of their respective group. Colored boxes include the first and third quartile. Black vertical whiskers show the largest and smallest value no further than 1.5 times the inter-quartile range. Black dots are points that fall outside the 1.5 times the inter-quartile range 
the Chilean (whaling) sample. In the head comparisons however, there is overlap in the distribution (center panel in Fig. 3). The distributions do not overlap in the comparisons of tail measurements between these 2 data sets. The statistical differences found in relative head and tail lengths could be a product of differences in the variance for the 2 data sets (Fig. 3) that most likely result from the small sample size of the Chilean (drone) data set.

LeDuc et al. (2017) highlighted the differences between aerial photogrammetry data (Gilpatrick \& Perryman 2008) and whaling data (Branch et al. 2007) as a main area of uncertainty regarding the subspecies status of the Chilean blue whale because the 2 methodologies indicate differing patterns. Since LeDuc et al. (2017), additional data from Japanese whaling records from Chile have become available to support the intermediate body size and unique status of Chilean blue whales (Pastene et al. 2020). Biases could arise from both methods of data collection, including (but not limited to) a positive bias in whaling measurements due to stretching and a negative bias in drone measurements because the tail was more submerged than the majority of the body during surfacing events.

The practice of stretching whales with winches on the flensing deck is a possible source of positive length bias for some historical measurements. Whale stretching would not impact absolute head length, but could impact all other measures including relative head length. This most likely did not affect Antarctic blue whale measurements because they were often much larger than the minimum catch length regulation of $21.3 \mathrm{~m}$, but sexually mature female pygmy blue whales and presumably Chilean blue whales were more susceptible to stretching during measurement collection due to their size being closer to catch regulation length (Branch et al. 2007). While the overall global whaling records for both pygmy and Chilean blue whales show signs of whale stretching (Branch et al. 2007), the 58 pygmy blue whales and the 56 Chilean (whaling) data included in our analyses were likely not subjected to this practice for several reasons (see Pastene et al. 2020 for details).

We took care to reduce possible negative bias in drone measurements by removing data from animals that were not photographed absolutely flat on the surface, only selecting the longest image of a given whale, and using conservative size limits to restrict the possibility of immature whales in our data. Moreover, Durban et al. (2016) quantified measurement bias from the drone images and found it to be small.
Using blue whale data collected in 2015, Durban et al. (2016) validated the accuracy of the drone photogrammetry method by collecting aerial image measurements of their research vessel 7 different times across $4 \mathrm{~d}$ and comparing the measured lengths to the known length of the research vessel $(18.6 \mathrm{~m})$. They found the average measurement bias to be only $0.03 \mathrm{~m}$, which represents $<0.002 \%$ of the total length of the boat. The authors also estimated the variability of different length estimates of six whales with 4-7 repeat images. They showed $<5 \%$ variability around the mean (ranging from $3.0 \%-4.3 \%$ ). Although this length measurement bias seems small, the length differences between groups and the sample size are also small, so errors could impact our findings. Multiple photographs were measured when available, and the largest measurement of each whale was selected to represent that whale's length because the whale may have been slightly bent under the surface and a whale will never be shorter than the longest measured photograph. Tail length was significantly smaller in Chilean (drone) compared to Chilean (whaling) data, suggesting negative length bias in the drone data; however, we would expect this to affect all measurements, and the total length of Chilean blue whales collected from drones and whaling data were nearly identical.

Another unlikely possible explanation for the differences observed in tail proportions are that our drone data represent multiple populations (i.e. a mixed sample). Aguayo (1974) stated that both Antarctic and 'pygmy' (e.g. Chilean) blue whales were caught in Chilean waters, which could have explained the intermediate average body length found for Chilean blue whales. However, Branch et al. (2007) tested this possibility within their data and discredited it. Buchan et al. (2014) identified 2 blue whale songs belonging to southeast Pacific blue whales in Chilean waters (presumably the Chilean population), and these songs both had a strong seasonal pattern of presence in Chile during the austral summer and autumn when southeast Pacific blue whales are known to feed throughout Chilean waters (Thiele et al. 1998, Hucke-Gaete et al. 2004, Buchan et al. 2015). The Antarctic blue whale song was only detected in Chilean waters during the austral summer and autumn, which coincides with their summer feeding season in the Southern Ocean (Buchan et al. 2018). Interestingly, Buchan et al. (2018) noted that the Antarctic blue whale song was detected almost exclusively at the oceanic study sites off Chile (Northwest Chiloe, Guafo North), suggesting that Antarctic blue whales rarely enter the Gulfo Corcov- 
ado feeding areas. This pattern is despite both the oceanic and inner sea sites in southern Chile offering feeding habitat during the austral summer/autumn feeding season (Hucke-Gaete et al. 2004). Therefore, the presence of Antarctic blue whales solely at the oceanic sites suggests that Antarctic blue whales are migrating along the coast of Chile, but not using these waters as a primary feeding area. We only photographed whales in the inner sea feeding sites, so the likelihood that they were Antarctic blue whales is relatively low. Moreover, if we were to have sampled Antarctic blue whales the relative tail lengths would likely have been much larger than those observed, as this is the main distinguishing feature between Antarctic and pygmy blue whales (Ichihara 1966). Finally, Pastene et al. (2020) also noted that the 2 known sexually mature females (observed with calves) included in Durban et al. (2016) had the greatest probability of being Chilean blue whales (to the exclusion of pygmy or Antarctic blue whales) because their lengths (22.2 and $22.7 \mathrm{~m}$ ) were consistent with the whaling data for sexually mature Chilean blue whale females (Branch et al. 2007).

The discrepancy in relative tail length could possibly be a result of local extirpation and replacement of Chilean blue whales by pygmy blue whales. LeDuc et al. (2017) hypothesized that a local extirpation of Chilean blue whales may have occurred as a result of overharvesting, and thus the Chilean blue whale range was subsequently occupied by another group of blue whales extending their range. In other words, under this scenario, the Chilean blue whale subspecies identified by Branch et al. (2007) and Pastene et al. (2020) does not exist today. However, acoustic data do not support this hypothesis. The original recording of Chilean blue whale song was collected (Cummings \& Thompson 1971) only a few years after the collection of the morphological data by the Japanese whaling operation (1965-1966) detailed by Pastene et al. (2020). The structure described by Cummings \& Thompson (1971) has remained constant through time (Stafford et al. 1999). This temporal consistency, and the uniqueness of the acoustic pattern, suggest that an extinction-recolonization hypothesis is unlikely. Genotypic patterns among historical and contemporary samples from Chilean blue whales could test this hypothesis (see Alter et al. 2012).

\subsection{Subspecies comparisons}

Despite changes in data handling and statistics, our study confirms the morphological patterns found in Branch et al. (2007) and Pastene et al. (2020), including separation between Chilean, pygmy, and Antarctic blue whales. In addition to the inclusion of new drone data, we employed a different maturity size cut-off strategy for the morphological analyses than Pastene et al. (2020). The reason for doing this was that we were unable to determine the sex of individuals in our contemporary Chilean (drone) data. Therefore, we only considered individuals from each data set that met the estimated threshold for sexually mature females of that subspecies, as estimated by Pastene et al. (2020). Although this approach may have eliminated some sexually mature individuals, it would most likely remove males, as they tend to be smaller in length than females. To reiterate, despite the availability of sex-specific maturity cutoffs for the 3 historical data sets, we chose to use this larger cutoff to standardize the data and ensure that all whales within a subspecies had the same cut-off. This approach led to differences in sample sizes between our study and Pastene et al. (2020). Moreover, these authors also compared males and females separately for each subspecies. Despite this difference in approach, our findings showed the same results as Pastene et al. (2020) for the Chilean (whaling) data: intermediate in total body length between pygmy and Antarctic blue whales.

With all data combined, Chilean blue whales have significantly shorter heads (relative to body length) than Antarctic blue whales and significantly longer tails than pygmy blue whales according to our analyses. This pattern is contrary to the recent findings by Pastene et al. (2020), who showed a relatively clear distinction between pygmy and Chilean blue whales using historical morphological measurements from whaling records. Additional data are needed to increase confidence in these tests.

Our results are in alignment with acoustic, genetic, and distributional studies that support the Chilean blue whale as a unique subspecies. Blue whale song can be divided into at least 9 song types globally (McDonald et al. 2006), each of which is associated with a geographic region. The southeastern Pacific Ocean blue whale song has been known for some time (Cummings \& Thompson 1971, Stafford et al. 1999). It has been recorded off the Chilean coast (peaking in austral summer) and has been observed year-round off the coast of Peru. The southeastern Pacific Ocean (e.g. Chilean) blue whale song differs from the Antarctic blue whale song that has been reported from around the Southern Ocean (Ljungblad et al. 1998, Matsuoka et al. 2000, Širović et al. 2004). This Antarctic song type, however, has also 
been reported from tropical locations (Stafford et al. 2004), including the ETP and the Indian Ocean. Both the Antarctic and Chilean blue whale songs differ from the songs associated with the Indian Ocean pygmy blue whales. Within pygmy blue whales, 3 structurally similar songs have been detected in different locations of the Indian Ocean (Sri Lanka, Madagascar, and Australia). These different seasonal acoustic patterns within this subspecies strongly suggest population structure (McDonald et al. 2006, Stafford et al. 2011, Samaran et al. 2013). These acoustic data support a highly structured mosaic of blue whale diversity, with some temporal and spatial overlap (Samaran et al. 2010).

Genetic data from the Southern Hemisphere also support a unique Chilean blue whale subspecies that is significantly different from Antarctic and pygmy blue whales, with similar levels of differentiation between all 3 (LeDuc et al. 2007, 2017). Torres-Florez et al. (2014) compared genetic samples of blue whales from southern Chile, northern Chile, the ETP, and Antarctica. They found that there were no significant differences in mitochondrial DNA haplotype frequencies or nuclear DNA genotypes between blue whales from southern Chile, northern Chile, and the ETP, but all 3 of those regions were significantly different from the Antarctic blue whales for both the mitochondrial and microsatellite analyses. This suggests that Antarctica and Chile are occupied by genetically distinct populations of blue whales. Further analyses are needed to determine if these constitute unique subspecies based on genetic information (Martien et al. 2017, Taylor et al. 2017b). Furthermore, these findings support the hypothesis that Chilean blue whales use the ETP as a breeding area (Torres-Florez et al. 2014).

Chilean blue whales outfitted with implantable satellite tags migrated from Gulfo Corcovado to the Galapagos Archipelago in the southern ETP during the austral winter and spring when their breeding season in the ETP most likely occurs (Fig. 1 in HuckeGaete et al. 2018). Moreover, LeDuc et al. (2017) found that the northern and southern ETP are used differentially by blue whales from the Northern and Southern Hemisphere. Specifically, they found that blue whales from Chile had a significantly stronger tendency to use the southern ETP (the waters of Peru and Ecuador), while whales from the eastern north Pacific (ENP) tended to use the northern ETP (the Costa Rican Dome). Although some movement between these ETP regions has been observed (unpublished results described in LeDuc et al. 2017), overall the genetic data indicate a specific usage pattern of the ETP with spatial and temporal separation between Northern Hemisphere and Chilean blue whales (LeDuc et al. 2017). Chilean blue whales tend to occupy the southern ETP during the austral winter or boreal summer while the ENP blue whale population occupies the northern ETP during the austral summer or boreal winter (LeDuc et al. 2017). OrtegaOrtiz et al. (2018) examined morphological data (length of the tail relative to total body length) collected from aerial surveys from winter habitat of ENP blue whales (Gulf of California, Mexico) and found support for the hypothesis of separate ENP and Indian Ocean pygmy blue whales. In addition, these authors highlight issues from a previous study (Gilpatrick \& Perryman 2008) that examined aerial measurements of ENP blue whales from California to Central America collected in the boreal summer and fall, when most of the whales in the ETP would have been from the southeastern Pacific Ocean (e.g. Chilean). Gilpatrick \& Perryman (2008) compared these measurements to other blue whales and found morphological similarities between whales in the ENP and Indian Ocean pygmy blue whales (the latter from whaling data). Ortega-Ortiz et al. (2018) did not contrast morphology between ENP whales and Chilean blue whales due to a lack of data for the latter, and therefore offer no insights into Chilean blue whales directly. However, one of the main findings from their work was a similarity in the relative caudle peduncle length between ENP blue whales and Antarctic blue whales from South Georgia Island. The authors suggest that the shorter relative tail length reported by Gilpatrick \& Perryman (2008) could be a result of combining ENP and Chilean blue whales. This makes sense in light of our results, which show Chilean and Indian Ocean pygmy blue whales with similar relative head and tail lengths, combined with the similarities found by Ortega-Ortiz et al. (2018) between ENP and Antarctic blue whales killed near South Georgia Island.

\subsection{Intraspecific blue whale relationships}

Without an intraspecific phylogeographic analysis we can only speculate as to the relationships of these different subspecies. Chilean blue whales appear to resemble pygmy blue whales in total body and relative head length. One explanation could be that they share a common ancestral population that occupied the subantarctic waters and subsequently split via vicariance due to continental barriers. Alternatively, these similarities in relative head and tail length 
could be the result of convergent evolution. Chilean blue whales probably remain genetically distinct from the ENP population via the alternate synchronous seasonality of migration (as with other large whales). Interestingly, acoustic evidence shows that at least some Chilean blue whales are present yearround in the ETP (Buchan et al. 2015), so the possibility of some interbreeding between Chilean and Northern Hemisphere blue whales cannot be eliminated. This also has important implications for the range of Chilean blue whales and the need for yearround conservation throughout the ETP. Furthermore, since some Chilean blue whales migrate to the ETP outside of their breeding season, factors other than breeding may be driving their northward migration (see Hucke-Gaete et al. 2018 for discussion of feeding behavior near the Galapagos Islands). Conservation decisions for the Chilean blue whale population cannot be based solely on seasonal movements, since individuals seem to be distributed throughout Chilean waters and the ETP regardless of season. A better understanding of the mechanisms driving Chilean blue whale migration to the ETP, particularly during the austral summer when the majority of the population is feeding in Chilean waters, is essential for establishing effective conservation practices that can protect the resources that they utilize in the ETP year-round. In addition, an updated phylogeographic analysis of all blue whale subspecies would provide context to the relationships of subspecific diversity (e.g. Archer et al. 2013, Leslie \& Morin 2018).

\section{CONCLUSIONS}

Effective conservation strategies rely on accurate taxonomic boundaries. Unfortunately, cetaceans are vastly undercategorized (Taylor et al. 2017a), and the taxonomy of balaenopterid whales is especially confusing (Wada et al. 2003). Our results support a morphologically distinct Chilean blue whale with a total average body size intermediate to Antarctic and pygmy blue whales. These results add further support to morphological, acoustic, and genetic data used to construct the hypothesis that the Chilean blue whale is an independent group (McDonald et al. 2006, Branch et al. 2007, LeDuc et al. 2007, 2017, TorresFlorez et al. 2014, Buchan et al. 2018, Pastene et al. 2020). Williams et al. (2011) estimated a population size of 303 individuals for Chilean blue whales in 1997, at a minimum of 7.2-9.5\% estimated preexploitation numbers. Galletti Vernazzani et al. (2017) conducted a mark-recapture study at Isla Grande de Chiloé from 2004-2012, and their models estimated that approximately 570-760 Chilean blue whales use this area seasonally. Regardless, the need for continued conservation of this unnamed subspecies is critical to ensure recovery.

The contrasting patterns between Chile (whaling) and Chile (drone) data are likely an artefact of the relatively small data sets, or some unknown vestige of the different methods used to measure whales on land and/or at sea. Continued data collection to increase the sampling of Chilean blue whales is needed, and future research should focus on collecting morphological data from blue whales throughout the Southern Hemisphere using non-invasive drones. In addition, an effort to compare drone-derived measurements from live and dead whales would help identify any artefacts of differential whaling and drone-based field measurements. This study has shown that as drones become an integral part of the field cetologist's toolkit, the morphological measurements collected from live free-ranging baleen whales can be used for systematic studies to help clarify the relationships and taxonomy of these species.

Acknowledgements. We are thankful to Foundation MERI (Melimoyu Ecosystem Research Institute) for logistical and funding support. Cruise support in 2017 was provided by the Dalio Foundation (now 'OceanX'). We also thank Thomas Rodney Montt, Felipe 'The Juice' Jugo, Nadine Lysiak, Daniel Casado, the captain and crew of the R/V 'Centinela', the staff of Pesquera Los Elefantes, and Pedro Montt. Don LeRoi and Aerial Imaging Solutions provided technical support. Uko Gorter (www.ukogorter.com/) provided blue whale illustrations for figures. We extend a special thanks to Wayne Perryman and Jim Gilpatrick for their advice and assistance. Drs. Steve Wang and Trevor Branch provided advice with statistics. We also thank Drs. Nick Pyenson and Jesus Maldonado at the Smithsonian Institution for their support.

\section{LITERATURE CITED}

Aguayo LA (1974) Baleen whales off continental Chile. In: Carleton RG, Schevill WE, Norris KS (eds) The whale problem: a status report. Harvard University Press, Cambridge, MA, p 209-217

Alter SE, Newsome SD, Palumbi SR (2012) Pre-whaling genetic diversity and population ecology in eastern Pacific gray whales: insights from ancient DNA and stable isotopes. PLOS ONE 7:e35039

Archer FI, Morin PA, Hancock-Hanser BL, Robertson KM and others (2013) Mitogenomic phylogenetics of fin whales (Balaenoptera physalus spp.): genetic evidence for revision of subspecies. PLOS ONE 8:e63396

Attard CR, Beheregaray LB, Jenner KC, Gill PC and others (2012) Hybridization of Southern Hemisphere blue whale subspecies and a sympatric area off Antarctica: 
Impacts of whaling or climate change? Mol Ecol 21: 5715-5727

Benjamini Y, Hochberg Y (1995) Controlling the false discovery rate: a practical and powerful approach to multiple testing. J R Stat Soc B 57:289-300

Branch TA, Mikhalev YA (2008) Regional differences in length at sexual maturity for female blue whales based on recovered Soviet whaling data. Mar Mamm Sci 24: 690-703

Branch TA, Matsuoka K, Miyashita T (2004) Evidence for increases in Antarctic blue whales based on Bayesian modelling. Mar Mamm Sci 20:726-754

Branch TA, Abubaker EMN, Mkango S, Butterworth DS (2007) Separating southern blue whale subspecies based on length frequencies of sexually mature females. Mar Mamm Sci 23:803-833

Buchan SJ, Hucke-Gaete R, Rendell L, Stafford KM (2014) A new song recorded from blue whales in the Corcovado Gulf, Southern Chile, and an acoustic link to the Eastern Tropical Pacific. Endang Species Res 23:241-252

Buchan SJ, Stafford KM, Hucke-Gaete R (2015) Seasonal occurrence of southeast Pacific blue whale songs in southern Chile and the eastern tropical Pacific. Mar Mamm Sci 31:440-458

Buchan SJ, Hucke-Gaete R, Stafford KM, Clark CW (2018) Occasional acoustic presence of Antarctic blue whales on a feeding ground in southern Chile. Mar Mamm Sci 34:220-228

Burmeister H (1871) Sobre Balaenoptera intermedia, B. patachonica y $B$. bonaerensis y sus caracteres distintivos. Boletín del Museo Público de Buenos Aires: 11-14

Clapham PJ, Baker CS (2018) Whaling, modern. In: Würsig B, Thewissen JGM, Kovacs KM (eds) Encyclopedia of marine mammals. Academic Press, London, p 1070-1074

Committee on Taxonomy (2019) List of marine mammal species and subspecies. Society for Marine Mammalogy. www.marinemammalscience.org (accessed 3 Jan 2020)

Cooke JG (2018) Balaenoptera musculus (errata version published in 2019). The IUCN Red List of Threatened Species 2018:e.T2477A156923585. https://dx.doi.org/10.23 05/IUCN.UK.2018-2.RLTS.T2477A156923585.en (accessed 3 Jan 2020)

Cummings WC, Thompson PO (1971) Underwater sounds from the blue whale, Balaenoptera musculus. J Acoust Soc Am 50:1193-1198

KDinno A, Dinno MA (2017) Package 'dunn. test' dunn.test v1.3.5. https://cran.r-project.org/web/packages/dunn.test/ index.html

Dunn (1961) Multiple comparisons among means. J Am Stat Assoc 56:52-64

Dunn (1964) Multiple comparisons using rank sums. Technometrics 6:241-252

* Durban JW, Moore MJ, Chiang G, Hickmott LS and others (2016) Photogrammetry of blue whales with an unmanned hexacopter. Mar Mamm Sci 32:1510-1515

Galletti Vernazzani B, Jackson JA, Cabrera E, Carlson CA, Brownell Jr RL (2017) Estimates of abundance and trend of Chilean blue whales off Isla de Chiloé, Chile. PLOS ONE 12:e0168646

Gilpatrick JW, Perryman WL (2008) Geographic variation in external morphology of North Pacific and Southern Hemisphere blue whales (Balaenoptera musculus). J Cetacean Res Manag 10:9-21

Goebel ME, Perryman WL, Hinke JT, Krause DJ, Hann NA, Gardner S, LeRoi DJ (2015) A small unmanned aerial system for estimating abundance and size of Antarctic predators. Polar Biol 38:619-630

Hucke-Gaete R, Osman LP, Moreno CA, Findlay KP, Ljungblad DK (2004) Discovery of a blue whale feeding and nursing ground in southern Chile. Proc R Soc B 271: S170-S173

*Hucke-Gaete R, Bedrinana-Romano L, Viddi FA, Ruiz JE, Torres-Florez JP, Zerbini AN (2018) From Chilean Patagonia to Galapagos, Ecuador: novel insights on blue whale migratory pathways along the eastern South Pacific. PeerJ 6:e4695

*Hutchings JA, Reynolds JD (2004) Marine fish population collapses: consequences for recovery and extinction risk. Bioscience 54:297-309

Ichihara T (1966) The pygmy blue whale, Balaenoptera musculus brevicauda, a new subspecies from the Antarctic. In: Norris KS (ed) Whales, dolphins, and porpoises. University of California Press, Berkeley and Los Angeles, CA, p 79-111

Kruskal WH, Wallis A (1952) Use of ranks in one-criterion variance analysis. J Am Stat Assoc 47:583-621

LeDuc RG, Dizon AE, Goto M, Pastene LA and others (2007) Patterns of genetic variation in Southern Hemisphere blue whales and the use of assignment test to detect mixing on the feeding grounds. J Cetacean Res Manag 9:73-80

* LeDuc RG, Archer FI, Lang AR, Martien KK and others (2017) Genetic variation in blue whales in the eastern Pacific: implication for taxonomy and use of common wintering grounds. Mol Ecol 26:740-751

* Leslie MS, Morin PA (2018) Structure and phylogeography of two tropical predators, spinner (Stenella longirostris) and pantropical spotted (S. attenuata) dolphins, from SNP data. R Soc Open Sci 5:171615

Linnaeus C (1758) Systema naturae per regna tria naturae, secundum classes, ordines, genera, species, cum characteribus, differentiis, synonymis, locis. Editio decima, reformata. Laurentius Salvius, Holmiae

Ljungblad DK, Clark CW, Shimada H (1998) A comparison of sounds attributed to pygmy blue whales (Balaenoptera musculus brevicauda) recorded south of the Madagascar Plateau and those attributed to 'true' blue whales (Balaenoptera musculus) recorded off Antarctica. Rep Int Whaling Comm 48:439-442

Mackintosh NA, Wheeler JFG (1929) Southern blue and fin whales. Discov Rep 1:257-540

Martien KK, Leslie MS, Taylor BL, Morin PA and others (2017) Analytical approaches to subspecies delimitation with genetic data. Mar Mamm Sci 33(Spec Issue):27-55

Matsuoka K, Murase H, Nishiwaki S, Fukuchi T, Shimada H (2000) Development of a retrievable sonobuoy system for whale sounds recording in polar region. Paper SC/52/O7 presented to the IWC Scientific Committee, June 2000, Adelaide

McDonald MA, Mesnick SL, Hildebrand JA (2006) Biogeographic characterization of blue whale song worldwide: using song to identify populations. J Cetacean Res Manag 8:55-65

Omura H (1984) Measurements of body proportions of the pygmy blue whale, left by the late Dr. Tadayoshi Ichihara. Sci Rep Whales Res Inst 35:199-203

* Ortega-Ortiz CD, Gómez-Muñoz VM, Gendron D (2018) Allometry and morphometry of blue whales photographed in the Gulf of California: insights into subspecies taxonomy in the Eastern North Pacific. Endang Species Res 37: 183-194 
Pastene LA, Acevedo J, Branch TA (2020) Morphometric analysis of Chilean blue whales and implications for their taxonomy. Mar Mamm Sci 36:116-135

Pollock CM (2019) Balaenoptera musculus ssp. brevicauda. The IUCN Red List of Threatened Species 2019: e.T2479A13650873. https://www.iucnredlist.org/species/ 2479/136508733 (accessed 10 Jan 2020)

R Core Team (2020) R: a language and environment for statistical computing. R Foundation for Statistical Computing, Vienna

Samaran F, Adam O, Guinet C (2010) Discovery of a mid-latitude sympatric area for two Southern Hemisphere blue whale subspecies. Endang Species Res 12:157-165

Samaran F, Stafford KM, Branch TA, Gedamke J, Royer JY, Dziak RP, Guinet C (2013) Seasonal and geographic variation of southern blue whale subspecies in the Indian Ocean. PLOS ONE 8:e71561

Schneider CA, Rasband WS, Eliceiri KW (2012) NIH Image to ImageJ: 25 years of image analysis. Nat Methods 9: 671-675

Širović A, Hildebrand J, Wiggins SM, McDonald M, Moore SE, Thiele D (2004) Seasonality of blue and fin whale calls west of the Antarctic Peninsula. Deep Sea Res II 51: 2327-2344

Stafford KM, Nieukirk SL, Fox CG (1999) Low-frequency whale sounds recorded on hydrophones moored in the eastern tropical Pacific. J Acoust Soc Am 106: 3687-3698

Stafford KM, Bohnenstiehl DR, Tolstoy M, Chapp E, Mellinger DK, Moore SE (2004) Antarctic-type blue whale calls recorded at low latitudes in the Indian and eastern Pacific Oceans. Deep Sea Res I 51:1337-1346

Stafford KM, Chapp E, Bohnenstiel DR, Tolstoy M (2011)

Editorial responsibility: B. Louise Chilvers, Palmerston North, New Zealand
Seasonal detection of three types of 'pygmy' blue whale calls in the Indian Ocean. Mar Mamm Sci 27:828-840

Taylor BL, Archer FI, Martien KK, Rosel PE and others (2017a) Guidelines and quantitative standards to improve consistency in cetacean subspecies and species delimitation relying on molecular genetic data. Mar Mamm Sci 33(Spec Issue):132-155

Taylor BL, Perrin WF, Reeves RR, Rosel PE and others (2017b) Why we should develop guidelines and quantitative standards for using genetic data to delimit subspecies for data-poor organisms like cetaceans. Mar Mamm Sci 33(Spec Issue):12-26

Thiele D, Pijanowski B, Ljungbald D (1998) A note on blue whale sightings in the southern Chilean Fjords. Paper No. SC50/OGW/WP2 presented to the International Whaling Commission Scientific Committee, 16-20 May 1998, Muscat

* Torres-Florez JP, Hucke-Gaete R, LeDuc R, Lang A and others (2014) Blue whale population structure along the eastern South Pacific Ocean: evidence of more than one population. Mol Ecol 23:5998-6010

* Torres-Florez JP, Olson PA, Bedriñana-Romano L, Rosenbaum H, Ruiz J, LeDuc R, Hucke-Gaete R (2015) First documented migratory destination for eastern South Pacific blue whales. Mar Mamm Sci 31:1580-1586

*Wada S, Oishi M, Yamada T (2003) A newly discovered species of living baleen whale. Nature 426:278-281

Wickham H (2016) ggplot2: elegant graphics for data analysis. Springer-Verlag, New York, NY

Williams R, Hedley SL, Branch TA, Bravington MV, Zerbini AN, Findlay KP (2011) Chilean blue whales as a case study to illustrate methods to estimate abundance and evaluate conservation status of rare species. Conserv Biol 25:526-535

Submitted: March 27, 2020; Accepted: July 24, 2020

Proofs received from author(s): October 14, 2020 